\title{
The Acceptance of Educational Data Mining Technology among Students in Public Institutions of Higher Learning in Malaysia
}

\author{
Muslihah Wook, Zawiyah M. Yusof, and Mohd Zakree Ahmad Nazri
}

\begin{abstract}
Accepting the emergence of data mining technology by students is crucial to the successful implementation of the technology in education institutions. Although previous studies have empirically show the result of acceptance or adoption of data mining technology in numerous fields, however, they are focused at organisational-level. Hence, there is a need to explain what are the determinants could influence the acceptance of data mining technology at individual-level since they are the most affected by the technology. Therefore, this study adapts selected constructs in the Technology Acceptance Model 3 (TAM3) to conceptualise the research problem, namely in terms of perceived usefulness, perceived ease of use, relevance for analysing, anxiety of educational data mining technology, self-efficacy and facilitating conditions. To examine the model, this study surveyed 158 students from four public Institutions of Higher Learning in Malaysia. Pearson product-moment correlation coefficient is utilised to analyses the relationship between the constructs. The findings have revealed that most of the constructs have a high level of correlation.
\end{abstract}

Index Terms-Acceptance, data mining, educational data mining, institutions of higher learning (IHLs), technology acceptance model 3 (TAM3).

\section{INTRODUCTION}

Data mining (DM) technology has become new paradigms to enhance the scope, quality, efficiency and achievements of educational system [1]. In particular, users increasingly benefit from the technology that provides special data interpretation and processing techniques [2]. With such capabilities, DM is now considered one of promising technologies for education [3] which commonly known as educational data mining (EDM). Earlier educational system faced a number of challenges; lack of significant knowledge for evaluating, planning, monitoring and marketing [4]. Hence, EDM has gained significant interest as suitable and realistic next-generation computer-based educational systems (CBES), which offers a potential solution to these challenges [5].

In spite of the rapidly growing popularity of DM in the educational environment, most of studies have emphasize more on the technical aspect of DM application

Manuscript received October 10, 2014; revised January 13, 2015.

Muslihah Wook is with the Faculty of Defence Science and Technology, National Defence University of Malaysia, Sungai Besi Camp, 57000 Kuala Lumpur, Malaysia (e-mail: muslihah@upnm.edu.my).

Zawiyah M. Yusof and Mohd Zakree Ahmad Nazri are with Faculty of Information Science and Technology, National University of Malaysia, 43600 Bangi, Selangor, Malaysia (e-mail: zmy@ftsm.ukm.my; mzan@ftsm.ukm.my). algorithms-ignoring the users' perception of the technology [6]-[8]. Moreover, there has been a lack of study analysing how users use the technology [9]. Therefore, it is important to identify user behaviour prior to implement the EDM technology, as this could help minimising underutilisation or eventual abandonment.

\section{Educational Data Mining (EDM)}

EDM has been defined as "the area of scientific inquiry centred around the development of methods for making discoveries within the unique kinds of data that come from educational settings" [10]. It is also refers as the application of DM techniques to specific types of datasets originating from an educational context [6], [11], [12]. Since its emergence, EDM has gained significant educational attention as a promising CBES in which it concerned on how to analyse large-scale educational data for better understanding about learning and how to provide information regarding the learning process [13]. EDM is oriented to mine raw data extracted from traditional and web-based educational systems that might assist operative, tactical and strategic educational activity [5]. Fig. 1 illustrates the application of DM to the design of educational systems.

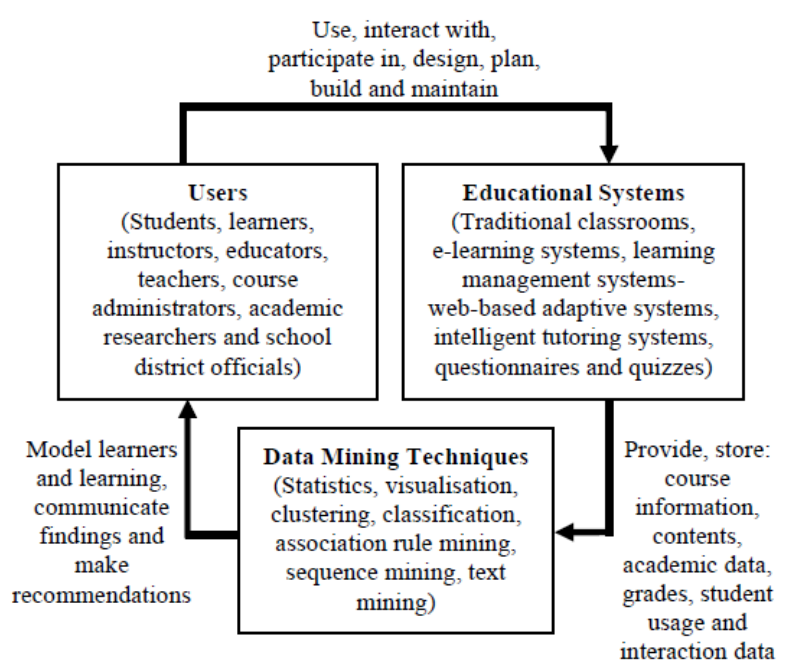

Fig. 1. Iterative cycle of data mining to the design of educational system[13].

EDM is capable of exploring the unique types of data in educational databases [12]. This may help improve the quality educational data analysis on a large-scale [14] for proactive and knowledge-driven decision-making [15]. Furthermore, EDM is also possible to improve the learning process and guide students' learning [16]. Table I depicts the main EDM application or task according to their goal. 
TABLE I: EDUCATIONAL DATA Mining APPLICATION/TASK [12], [16]

\begin{tabular}{|c|c|}
\hline Application/task & Goal \\
\hline $\begin{array}{l}\text { Analysis and } \\
\text { visualisation of data }\end{array}$ & $\begin{array}{l}\text { To highlight useful information and support } \\
\text { decision making }\end{array}$ \\
\hline $\begin{array}{l}\text { Providing feedback } \\
\text { for supporting } \\
\text { instructors }\end{array}$ & $\begin{array}{l}\text { This feedback is also used to support course } \\
\text { authors/teachers/administrators in decision } \\
\text { making }\end{array}$ \\
\hline $\begin{array}{l}\text { Recommendations } \\
\text { for students }\end{array}$ & $\begin{array}{l}\text { According to the student's profile, the system } \\
\text { can give him/her some personalised activities, } \\
\text { links to visits, new tasks or problems }\end{array}$ \\
\hline $\begin{array}{l}\text { Predicting student's } \\
\text { performance }\end{array}$ & $\begin{array}{l}\text { To estimate unknown values that describe the } \\
\text { student }\end{array}$ \\
\hline Student modelling & $\begin{array}{l}\text { To develop cognitive models of human } \\
\text { users/students, including a modelling of their } \\
\text { skills and declarative knowledge }\end{array}$ \\
\hline $\begin{array}{l}\text { Detecting } \\
\text { undesirable student } \\
\text { behaviours }\end{array}$ & $\begin{array}{l}\text { Some patterns of unusual behaviour or some } \\
\text { type of problem may be detected and, in this } \\
\text { manner, erroneous actions, low motivation, } \\
\text { academic failure and the dropping out of } \\
\text { students, may be identified as potential } \\
\text { problems and thus avoided }\end{array}$ \\
\hline Grouping students & $\begin{array}{l}\text { To group students according to their customised } \\
\text { features and personal characteristics }\end{array}$ \\
\hline $\begin{array}{l}\text { Social network } \\
\text { analysis }\end{array}$ & Studying relationships between individuals \\
\hline $\begin{array}{l}\text { Developing concept } \\
\text { maps }\end{array}$ & $\begin{array}{l}\text { To help instructors/educators in the automatic } \\
\text { process of developing/constructing concept } \\
\text { maps }\end{array}$ \\
\hline $\begin{array}{l}\text { Constructing } \\
\text { courseware }\end{array}$ & $\begin{array}{l}\text { To help instructors and developers to carry out } \\
\text { the construction/development process of } \\
\text { courseware and to learn contents automatically }\end{array}$ \\
\hline $\begin{array}{l}\text { Planning and } \\
\text { scheduling }\end{array}$ & $\begin{array}{l}\text { To plan future courses, student course } \\
\text { scheduling, planning resource allocation, } \\
\text { admission and counselling processes and } \\
\text { developing curriculum }\end{array}$ \\
\hline
\end{tabular}

Numerous tools are able for mining educational data, such as Clementine, WEKA, XLMiner, IlliMine and SAS Miner, among others. However, most of these tools are rarely used for educational problems [17]. Therefore, many DM tools have been developed to address a wide range of EDM application/task [12] for example EPRules, GISMO and TADA-ED. Recently, there are several novel EDM tools such as Java desktop Moodle mining, Logic Question Generator, Workbench, Learner Interaction Monitoring System and Continuous Improvement of e-Learning Courses Framework that encounter for extraction, learning support, feature engineering, visualisation and analysis support respectively [1].

Despite the fact that EDM tools are potentially able to shape modern advanced educational systems, they are complex and beyond the scope of what users may want to use [6], [7], as the tools are almost always used for comparing various methods, techniques and algorithms. Moreover, the design of the tools are argued to be simple rather than sophisticated and flexible [12]. Therefore, prior to employing the EDM tool in IHLs, the user's acceptance of the EDM technology will have to be made known [6] since not all users understand such technology[8].

\section{Studies of Data Mining Technology And The ADOPTION OF TAM}

Understanding the determinants that could influence users in accepting or adopting EDM technology is challenging-since everyone has their own predicament regarding perspectives. While studies related to DM technology adoption have been extensively conducted in banking [18], finance [19], accounting [20], telecommunications [21], insurance [22], business [23], [24], multiple industries [25], small and medium enterprises [26] and education [27]. Most of these studies emphasis on organisational-level except a study by [24] which studied at individual-level. Furthermore, as far as this study is concerned, only [27] has been studied in the educational context and it has been carried out in USA. No study has ever been carried out in Malaysia yet. This has eventually called for a study on user acceptance of DM technology in the educational context particularly at the individual-level.

Studies by [28]-[36], have successfully used and extended Technology Acceptance Model (TAM) for predicting and explaining individual technology acceptance based on the internal psychological beliefs of the individual user. TAM proposes two important determinants to analyse what causes user to accept or reject new technology: perceived usefulness (PU) and perceived ease of use (PEOU) [29]-[32]. Perceived usefulness is defined as an individual's belief that using a particular technology could enhance job performance, and perceived ease of use refers to the degree to which an individual believes that a given technology would reduce job intensity [30]. TAM was later extended to TAM2, Unified Theory of Acceptance and Use of Technology (UTAUT), TAM3 and UTAUT2 for improving the classification of user determinants regarding the use of new technology. However, this study focuses on TAM3, which may be seen to be able to give a new, in-depth insight for explaining acceptance of EDM technology.

Reference [33] proposed TAM3, which is an integrated model (nomological network), for understanding individual-level information technology (IT) acceptance and usage. This model integrats the determinants of perceived usefulness (i.e., TAM2) [31] and perceived ease of use [34], but both determinants did not cross-over. It means that determinants of perceived usefulness could not influence perceived ease of use and vice versa. The idea of separation is due to the determinants of perceived usefulness are outcome-oriented anchors (i.e., subjective norm, image, job relevance, output quality and result demonstrability) [31], whereas perceived ease of use is expected to have a process-oriented anchors (i.e., computer self-efficacy, facilitating conditions, computer anxiety and computer playfulness) [34]. Although there are many potential determinants that could be included into the framework, only four specific determinants are chosen because of their strong support from previous studies. In addition, the determinants have also been modified for applicability in the context of EDM technology. The conceptual framework of this study is given in Fig. 2.

\section{A. Perceived Ease of Use (PEOU) and Perceived Usefulness (PU)}

TAM posits that perceived ease of use would have a positive effects on perceived usefulness [31]. Previous studies have found that perceived ease of use DM technology [24], [35] are positively associated with perceived usefulness. In a similar vein, this study defines perceived ease of use as the degree to which users believe that using EDM technology would reduces their job intensity and predicts that it will have 
similar positive effects on perceived usefulness. Hence, the following association is hypothesized:

H1: There is a positive relationship between perceived ease of use and perceived usefulness of EDM technology.

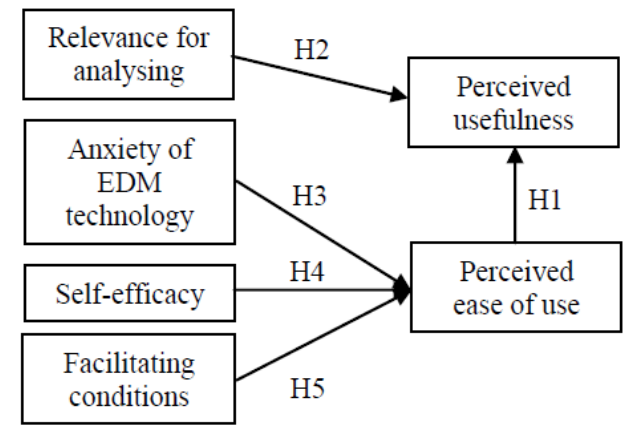

Fig. 2. Proposed conceptual framework.

\section{B. Relevance for Analysing (RA) and Perceived Usefulness (PU)}

Reference [31] introduced the concept of job relevance to clarify the capability of technology to support individual in implementing their task. Job relevance means the individual's perception that technology is applicable to users' jobs [24]. Reference [36] examined the job relevance construct towards e-learning systems, but called it 'relevance for learning' to explain the use of such technology for learning and performing learning-related tasks.

Following [36], this study has renamed the job relevance construct as 'relevance for analysing' since the DM technology's main feature is to analysing large amounts of data [37] in order to get informed decisions-instead of guesswork decisions [38]. Reference [31] stated that job relevance is a cognitive process that could affects the perceived usefulness of technology. Previous studies have shown job relevance [24], [31], [33], [35] and relevance for learning [36] have positively significant influence on perceived usefulness. Hence, it is hypothesized that:

$\mathrm{H} 2$ : There is a positive relationship between relevance for analysing and perceived usefulness of EDM technology.

\section{Anxiety of Educational Data Mining Technology (ANX) and Perceived Ease of Use (PEOU)}

Anxiety of technology is the users' emotional reaction when confronted with a new technology. Reference [34] examines this emotional reaction on computer technology and hypothesized it as a negative affective reaction towards computer use. Previous studies revealed that computer anxiety is a significantly negative impact on the perceived ease of use [33], [34].

With the increasing pervasiveness computer technologies now produces a wide range of technology-specific features, further study is needed to examine the users' emotions toward a specific technology compared computer technology in general. For instance, Ref. [24] studied the adoption of DM tools for business online community, however, the results showed insignificant negative relationship of emotional factor on perceived ease of use. This is due to Ref. [24] still examines the users' emotion towards computer technology instead of DM technology specifically.

Thus, this study decided to rename the computer anxiety as 'anxiety of EDM technology' to suit it in this study setting.
Following the previous studies on computer anxiety [24], [31], [33], [35], [36], anxiety of EDM technology is proposed to have negative impact on the perceived ease of use. In other words, the increasing level of users' anxiety on EDM technology, the perceived ease of use the technology is decreased. Therefore, it is hypothesized that:

H3: There is a negative relationship between anxiety of educational data mining technology and perceived ease of use of the technology.

\section{Self-Efficacy (SE) and Perceived Ease of Use (PEOU)}

Self-efficacy construct has been largely demonstrated in computer applications [24], [33], [36], [39], but little study has been demonstrated it in a specific domain. Computer self-efficacy refers to individual's beliefs in their own ability to perform a specific task with the use of a computer [40]. In a specific domain (e.g., Youtube), Youtubeself-efficacy denotes as the ability of individual to find information on Youtube[41]. To enrich the user acceptance of EDM technology, this study conceptualizes self-efficacy construct as individual skill/knowledge in using EDM technology for analysing educational data. Previous studies show that high efficacy of user on technology could increase the perceived ease of use of the technology [24], [33], [39]. Therefore, it is hypothesized as follows:

H4: There is a positive relationship between self-efficacy and perceived ease of use of EDM technology.

\section{E. Facilitating Conditions (FC) and Perceived Ease of Use (PEOU)}

Facilitating conditions is a construct relating to external factors (i.e., environment) [34], particularly individual perception of resource facilitating conditions [42]. Individual believes the perception of external control is through organizational support facility for the available use of technology [33]. Reference [43] argued the facilitating conditions are related to the perception of resources or the technical infrastructure of the organization that could help users to use technology efficiently. Since DM is a complex technology (i.e., advance processes and algorithms) [24] make it difficult to use if there is no technical infrastructure support and available resources.

Past studies show the technical facilities have a significant influence on the use of DM technology [25] and the successful implementation of the technology in organisation [23], [44]. Reference [24] confirmed that the facilitating conditions have a significant influence on the perception ease of use DM technology. In this study context, the application of DM technology in educational environment requires IHLs to provide necessary resources and technical infrastructures in order to allow users to use the technology easily. Therefore, it is hypothesized that:

H5: There is a positive relationship between facilitating conditions and perceived ease of use of EDM technology.

\section{METHOD}

A number of studies (i.e., [18]-[24]) have revealed that the use of a survey by questionnaire is an acceptableinstrumen. Following the previous studies, this study employed the questionnaire method to test the hypothesized relationships 
on the acceptance of individual-level users toward DM technology in educational context.

\section{A. Population and Sample}

The population for the study are students from four different public IHLs in Malaysia. These students were second and third year undergraduate students who attended a Data Mining course in semester II session 2013/2014.The questionnaire was initially distributed to 250 students, however, a total of 165 questionnaires were answered (66\% return rate). Seven questionnaires are not processed due the missing data is more than $10 \%$ [45]. Therefore, the total of 158 questionnaires could be used and analysed in this study.

\section{B. Measurement}

The questionnaire was developed based on measurements adapted from [24] and [33] and they are modified to suit the educational context. Each construct has four items that are measured using a seven-point Likert scale ranging from $1=$ strongly disagree to $7=$ strongly agree. The pre-test is carried out to ensure the validity of the question. Validity is concerned with the concept that is well defined by the measure[46]. This test was involved two undergraduate students, three graduate students and two experts in DM technology and statistics respectively. The questionnaire is then pilot-tested with 23 undergraduate students for testing the reliability of the constructs. Reliability refers to the consistent in what it is intended to measure [46]. After the pilot-test, the Cronbach's alphas is calculated and confirmed that all constructs have greater than the recommended value of 0.70 [45]. The reliability for the constructs ranges between 0.74 and 0.94 , suggesting that the instrument is reliable and is suitable to measure the concepts in this study.

TABLE II: DEMOGRAPHIC CONSTRUCTS ON GENDER, AGE AND EXPERIENCE WITH DATA MINING TECHNOLOGY

\begin{tabular}{lcc}
\hline \hline Descriptions & Frequency & Percentage \\
\hline Gender & 71 & \\
Male & 87 & 44.9 \\
Female & 158 & 55.1 \\
Total & & 100 \\
\hline Age & 1 & \\
Less than 20 years old & 157 & 0.6 \\
20-29 years old & 0 & 99.4 \\
Over 30 years old & 158 & 0 \\
Total & & 100 \\
\hline Experience with Data Mining & & \\
Technology & 147 & \\
Less than 1 year & 11 & 93.0 \\
1-3 years & 0 & 7.0 \\
Over 4 years & 158 & 0 \\
Total & & 100 \\
\hline \hline
\end{tabular}

\section{DATA ANALYSIS AND RESUltS}

The statistical methods used for analysing the data are devided into three stages: (i) descriptive statistics, (ii) assessment of normality of data distribution and reliability values, and (iii) hypotheses testing. The descriptive statistics have been carried out todesribe the respondents' demographic constructs (categorical) and the adapted TAM3 constructs (continuous). This study then revealed the assessment of normality of data distribution by calculating the skewness and kurtosis values. The reliability values for each construct can be performed with the Cronbach's alpha value. Finally, the hypotheses are tested by using the Pearson product-moment correlation analysis.

\section{A. Descriptive Statistics}

The descriptive statistics of respondents' demographic constructs are presented in Table II.

Based on the above table, there were 71 (44.9\%) male and $87(55.1 \%)$ female respondents involved in the study. Most of them age between 20 to 29 years old (99.4) and 147 (93\%) have less than 1 year experience with DM technology.

Meanwhile, the descriptive statistics for each continuous constructs are shown in Table III.

TABLE III: MEAN, STANDARD DEVIATION (SD)

\begin{tabular}{lcc}
\hline \hline Variables & Mean & SD \\
\hline RA & 5.31 & .84 \\
ANX & 3.51 & 1.28 \\
SE & 4.34 & 1.01 \\
FC & 4.79 & .96 \\
PEOU & 4.64 & 1.02 \\
PU & 5.01 & .95 \\
\hline \hline
\end{tabular}

Based on the 158 responses, the means ranging from 3.51 to 5.31 , and standard deviations were between 0.84 and 1.28 , indicating that all constructs recorded moderate scores.

\section{B. Normality of Data Distribution and Reliability Values}

Prior to further data analyses, it is essential to screen the normality of data distribution in the early stage of any multivariate analyses [46]. The assessment of normality of data can be done through the calculation of the skewness (measure the symmetry of a distribution) and kurtosis (measure of the peakedness or flatness of a distribution) values, as suggested in[46]. The skewness value should less than 3, while the kurtosis value should less than 10. While some other studies indicate both skewness and kurtosis should be ranged within \pm 1.96 [47], others state that it should be ranged within \pm 2 [48]. Table IV shows the results of testing the normality of data distribution for each single construct through the range of skewness and kurtosis values.

The results (see Table IV) show that the skewness values range from -.296 to .121 , and the kurtosis values range from -.744 to 1.003 . Therefore, both skewness and kurtosis values are within the acceptable range, establishing the fact that the data is normally distributed in each construct.

TABLE IV: RESUltS OF TESTING THE NORMALITY OF DATA DiSTRIBUTION AND RELIABILITY VALUES

\begin{tabular}{llccc}
\hline \hline No & Variables Name & Skewness & Kurtosis & $\begin{array}{c}\text { Cronbach's } \\
\text { Alpha }\end{array}$ \\
\hline 1 & RA & -.233 & -.083 & 0.87 \\
2 & ANX & -.167 & -.210 & 0.95 \\
3 & SE & -.296 & 1.003 & 0.87 \\
4 & FC & -.259 & -.052 & 0.88 \\
5 & PEOU & -.268 & -.084 & 0.93 \\
6 & PU & .121 & -.744 & 0.93 \\
\hline \hline
\end{tabular}

Note: Standard Error in Skewness is 0.193; Standard Error in Kurtosis is 0.384

Each construct in a questionnaire often involves measurement errors [24]. The reliability test can be utilised to encounter the problems. Reliability means the internal consistency of each construct [46] which can be calculated with the Cronbach's alpha value [49], [50]. The acceptable 
minimum value is 0.70 , however, value above 0.80 is preferable [46], [51]. Table IValso shows the internal item consistency for each construct is acceptable (all values are above 0.80 ) as reliable observed items ranges from 0.87 to 0.95 . Hence, the results indicate that the constructs are internally consistent and reliable.

\section{Hypotheses Testing}

The hypotheses testing can be performed by calculating the correlation analysis which able to explain the strength and direction of linear relationship between two constructs [51]. The acceptable range of correlation value is between \pm 0.70 and should not be greater, as it might cause multicollinearity (single independent variable is highly correlated with other independent variables) statistical problems[46].Since allthe adapted TAM 3 constructs are continuous, this study used the Pearson product-moment correlation coefficient to measure the strength of the relationship between each pair of the constructs. The result of correlation analysis of the study is shown in Table V.

TABLE V: CORRELATION ANALYSIS

\begin{tabular}{lcccccc}
\hline \hline Variables & RA & ANX & SE & FC & PEOU & PU \\
\hline RA & 1 & & & & & \\
ANX & -.10 & 1 & & & & \\
SE & $.25^{* *}$ & -.03 & 1 & & & \\
FC & $.47^{* *}$ & $-.13^{*}$ & $.40^{* *}$ & 1 & & \\
PEOU & $.45^{* *}$ & $-.20^{* *}$ & $.51^{* *}$ & $.54^{* *}$ & 1 & \\
PU & $.60^{* *}$ & $-.17^{*}$ & $.27^{* *}$ & $.46^{* *}$ & $.59^{* *}$ & 1 \\
\hline \hline
\end{tabular}

$* * p<0.01, * p<0.05$

Note: All one-tailed correlations

The above results show that all the constructs are significantly correlated in the expected direction (i.e., both positive and negative). The positive significant correlations are $\mathrm{PEOU} \rightarrow \mathrm{PU}(r=0.59, p<0.01), \mathrm{RA} \rightarrow \mathrm{PU}(r=0.60, p<0.01)$, $\mathrm{SE} \rightarrow \mathrm{PEOU} \quad(r=0.51, p<0.01)$ and $\mathrm{FC} \rightarrow \mathrm{PEOU} \quad(r=0.54$, $p<0.01)$. Whereas, ANX $\rightarrow$ PEOU $(r=-.20, p<0.01)$ shows the expected negative significant correlation.

The results of correlation analysis for testing each of hypotheses in this study are shown in Table VI.

Table VI also shows the strength levels for each linear relationship among constructs. According to [52], the strength levels of correlation are indicated as low $(0.10 /-0.10$ to $0.29 /-0.29)$, moderate $(0.3 /-0.3$ to $0.49 /-0.49)$ and high $(0.5 /-0.5$ to $1 /-1)$. Based on the guidelines, all the hypotheses have high value of correlation, except for $\mathrm{H} 3$.

TABLE VI: HyPOTHESES TESTING FOR THE RESEARCH MODEL

\begin{tabular}{cccc}
\hline \hline Hypotheses & Constructs & $\begin{array}{c}\text { Pearson } \\
\text { product-moment } \\
\text { correlation }\end{array}$ & Correlation level \\
\hline $\mathrm{H} 1$ & PEOU $\rightarrow$ PU & $.59^{* *}$ & High \\
H2 & $\mathrm{RA} \rightarrow$ PU & $.60^{* *}$ & High \\
H3 & $\mathrm{ANX} \rightarrow \mathrm{PEOU}$ & $-.20^{* *}$ & Low \\
$\mathrm{H} 4$ & $\mathrm{SE} \rightarrow \mathrm{PEOU}$ & $.51^{* *}$ & High \\
$\mathrm{H} 5$ & $\mathrm{FC} \rightarrow \mathrm{PEOU}$ & $.54 * *$ & High \\
\hline \hline$* p<0.01$ & & &
\end{tabular}

\section{CONCLUSION}

The findings of the study clearly indicate that all the proposed hypotheses are supported. The correlation between relevance for analysing and perceived usefulness of EDM technology shows the strongest relationship, followed by perceived ease of use and perceived usefulness, facilitating conditions and perceived ease of use, and finally, self-efficacy and perceived ease of use. These showed that students accept the usefulness of EDM technology for analysing academic data which could improve their performance. In spite of most students (93\%) have less than one year experience in DM technology, they have high confident and skill in using the technology. Meanwhile, the low level relationship between anxiety of EDM technology and perceived ease of use indicate the technology is highly accepted although it may be difficult to use.

It is common that any study has its limitation. Firstly, this study has adapted a number of selected constructs in TAM3 which might be insufficient to understand user's perception of EDM technology. Secondly, the sample of respondents is relatively small which could not used to generalise the overall population of DM users in IHLs in Malaysia. As this study emphasised only on quantitative approach, it is therefore suggested to consider qualitative approach in the future.

\section{REFERENCES}

[1] A. P. Ayala, "Educational data mining: A survey and a data mining-based analysis of recent works," Expert Syst. Appl., vol. 41, no. 4, pp. 1432-1462, Mar. 2014.

[2] J. A. Lara, D. Lizcano, M. A. Martínez, J. Pazos, and T. Riera, "A system for knowledge discovery in e-learning environments within the european higher education area - application to student data from open University of madrid, UDIMA," Comput. Educ., vol. 72, pp. 23-36, Mar. 2014.

[3] J. M. Spector, "Trends and research issues in educational technology," Malaysian Online J. Educ. Technol., vol. 1, no. 3, pp. 1-9, May 2013.

[4] N. Delavari, S. P. Amnuaisuk, and M. R. Beikzadeh, "Data mining application in higher learning institutions," Informatics Educ., vol. 7, no. 1, pp. 31-54, 2008.

[5] A. Peña-Ayala and L. Cárdenas, "How educational data mining empowers state policies to reform education: the Mexican case study," Educational Data Mining: Applications and Trends, vol. 524, pp. 65-101, 2014.

[6] C. Romero and S. Ventura, "Educational data mining: A review of the state of the art," IEEE Trans. Syst. Man Cybern., vol. 40, no. 6, pp. 601-618, 2010.

[7] E. García, C. Romero, S. Ventura, and C. D. Castro, "A collaborative educational association rule mining tool," Internet High. Educ., vol. 14, no. 2, pp. 77-88, Mar. 2011.

[8] J. A. Johnson, "Ethics of data mining and predictive analytics in higher education," Association for Institutional Annual Forum, pp. 1-24, 2013.

[9] P. Baepler and C. J. Murdoch, "Academic analytics and data mining in higher education," Int. J. Scholarsh. Teach. Learn., vol. 4, no. 2, pp. 1 9, 2010.

[10] R. S. J. D. Baker, "Data Mining for Education," International Encyclopedia of Education, 3rd ed., Oxford, UK: Elsevier, 2010, pp. $112-118$.

[11] C. Romero and S. Ventura, "Educational data mining: A survey from 1995 to 2005," Expert Syst. Appl., vol. 33, no. 1, pp. 135-146, Jul. 2007.

[12] C. Romero and S. Ventura, "Data mining in education," Wiley Interdiscip. Rev. Data Min. Knowl. Discov., vol. 3, no. 1, pp. 12-27, Jan. 2013.

[13] C. Romero, S. Ventura, M. Pechenizkiy, and R. S. J. d Baker, Handbook of Educational Data Mining. Minnesota: Taylor \& Francis Group, 2011, p. 513.

[14] G. Siemens and R. S. J. D. Baker, "Learning analytics and educational data mining: towards communication and collaboration," in Proc. the Learning Analytics and Knowledge Conference, 2012, pp. 252-254.

[15] M. S. Bhullar and A. Kaur, "Use of data mining in education sector," in Proc. the World Congress on Engineering and Computer Science, 2012, pp. 24-27.

[16] A. Fernández, D. Peralta, J. M. Benítez, and F. Herrera, "E-learning and educational data mining in cloud computing: an overview," Int. J. Learn. Technol., vol. 9, no. 1, pp. 25-52, 2014. 
[17] J. Ranjan and K. Malik, "Effective educational process: A data-mining approach," VINE, vol. 37, no. 4, pp. 502-515, 2007.

[18] N. Dahlan, T. Ramayah, and A. H. Koay, "Data mining in the Banking Industry: an exploratory study," in Proc. the International Conference 2002. Internet, Economy and Business, 2002, p. 6.

[19] S. C. Chang, H. C. Chang, C. H. Lin, and S. C. Kao, "The effect of organizational attributes on the adoption of data mining techniques in the financial service industry: An empirical study in Taiwan," Int. $J$. Manag., vol. 20, no. 4, pp. 497 - 503, 2003.

[20] M. S. A. Rahman, "Utilisation of data mining technology within the Accounting Information System in the public sector: a country study Malaysia," Ph.D dissertation, Faculty of Business, Univeristy of Tasmania, 2008.

[21] N. Dahlan, T. Ramayah, and L. L. Mei, "Readiness to adopt data mining technologies: An exploratory study of telecommunication employees in Malaysia," Lect. Notes Comput. Sci., vol. 25, no. 69, pp. $75-86,2002$.

[22] T. Ramayah, N. Dahlan, and R. P. Adni, "Employees' data mining readiness in the Malaysian insurance industry: A preliminary study," Int. J. Manag. Pract. Contemp. Thought, vol. 2, no. 1, pp. $18-27$, 2007.

[23] T. Y. Wah and Z. A. Bakar, "Investigating the status of data mining in practice," Informing Science, pp. 1406 - 1413, 2003.

[24] T. C. K. Huang, C. C. Liu, and D. C. Chang, "An empirical investigation of factors influencing the adoption of data mining tools," Int. J. Inf. Manage., vol. 32, no. 3, pp. 257-270, Jun. 2012.

[25] H. R. Nemati and C. D. Barko, "Key factors for achieving organizational data-mining success," Ind. Manag. Data Syst., vol. 103, no. 4, pp. 282-292, 2003.

[26] E. Huang and T.-C. Chou, "Factors for web mining adoption of B2C firms: Taiwan experience," Electron. Commer. Res. Appl., vol. 3, no. 3 , pp. 266-279, Sep. 2004.

[27] K. E. Arnold, Z. Tanes, and A. S. King, "Administrative perceptions of data-mining software signals: promoting student success and retention," J. Acad. Adm. High. Educ., vol. 6, no. 2, pp. 29-40, 2010.

[28] F. D. Davis, "A technology acceptance model for empirically testing new end-user information systems: Theory and results," Ph.D dissertation, Sloan School of Management, Massachusetts Institute of Technology, 1986

[29] T. E. Rodriguez and P. M. Lozano, "The acceptance of Moodle technology by business administration students," Comput. Educ., vol. 58, no. 4, pp. 1085-1093, May 2012.

[30] F. D. Davis, "Perceived usefulness, perceived ease of use and user acceptance of information technology," MIS Q., vol. 13, no. 3, p. 319, 1989.

[31] V. Venkatesh and F. D. Davis, "Theoretical acceptance extension model: field four studies of the technology longitudinal," Manage. Sci., vol. 46, no. 2, pp. 186-204, 2000

[32] K. I. Al-Qeisi, "Analyzing the use of UTAUT model in explaining an online behaviour: Internet banking adoption," Ph.D dissertation, Dept. Marketing and Branding, Brunel University, 2009.

[33] V. Venkatesh and H. Bala, "Technology acceptance model 3 and a research agenda on interventions," Decis. Sci., vol. 39, no. 2, pp. 273-315, May 2008.

[34] V. Venkatesh, "Determinants of perceived ease of use: integrating control, intrinsic motivation, and emotion into the technology acceptance model," Inf. Syst. Res., vol. 11, no. 4, pp. 342-365, 2000.

[35] M. Hart, F. Esat, M. Rocha, and Z. Khatieb, "Introducing students to business intelligence: acceptance and perceptions of OLAP software," Informing Sci. Inf. Technol., vol. 4, pp. 105-123, 2007.

[36] Á. F. Agudo-Peregrina, Á. Hernández-García, and F. J. Pascual-Miguel, "Behavioral intention, use behavior and the acceptance of electronic learning systems: Differences between higher education and lifelong learning," Comput. Human Behav., vol. 34, pp. 301-314, Nov. 2014.

[37] H. Guruler, A. Istanbullu, and M. Karahasan, "A new student performance analysing system using knowledge discovery in higher educational databases," Comput. Educ., vol. 55, no. 1, pp. 247-254, Aug. 2010.

[38] H. R. Nemati and C. D. Barko, "Organizational data mining," Data Mining and Knowledge Discovery Handbook, pp. 1041 - 1048, 2010.

[39] V. Terzis and A. Economides, "The acceptance and use of computer based assessment," Comput. Educ., vol. 56, no. 4, pp. 1032-1044, May 2011.

[40] D. R. Compeau and C. A. Higgins, "Computer self-efficacy: development of a measure and initial test," MIS Q., vol. 19, no. 2, pp. 189-211, 1995.
[41] D. Y. Lee and M. R. Lehto, "User acceptance of youtube for procedura learning: An extension of the technology acceptance model," Comput. Educ., vol. 61, pp. 193-208, Feb. 2013

[42] S. Taylor and P. Todd, "Assessing IT usage: The role of prior experience," $M I S Q$., vol. 19, no. 4, pp. 561-570, 1995

[43] V. Venkatesh, M. G. Morris, G. B. Davis, and F. D. Davis, "User acceptance of information technology: Toward a unified view," MIS $Q$., vol. 27, no. 3, pp. 425-478, 2003.

[44] M. Hart, "Progress of organisational data mining in South Africa," ARIMA/SACJ, vol. 36, pp. 4-15, 2006.

[45] J. F. Hair, W. C. Black, B. J. Babin, and R. E. Anderson, Multivariate Data Analysis: A Global Perspective, 6th ed. Upper Saddle River: NJ Pearson Education, 2006.

[46] J. F. Hair, W. C. Black, B. J. Babin, and R. E. Anderson, Multivarite Data Analysis: A Global Perspective, 7th ed. Upper Saddle River: Pearson Education, 2010

[47] C. Y. Piaw, Asas Statistik Penyelidikan, 2nd ed. Malaysia: McGraw Hill Education, 2012.

[48] T. J. B. Kline, Psychological Testing: A Practical Approach to Design and Evaluation, 3rd ed. Thousand Oaks, CA: SAGE, 2005.

[49] J. C. Nunnally, Psychometric theory. New York: McGraw-Hill, 1978.

[50] U. Sekaran, Research Methods for Business - ASkill Building Approach, 4th ed. New York: John Wiley and Sons, 2005.

[51] J. Pallant, SPSS Survival Manual: A Step by Step Guide to Dato Analysis Using SPSS, 4th ed. NSW, Australia: Allen \& Unwin, 2011, p. 359.

[52] J. W. Cohen, Statistical Power Analysis for the Behavioural Sciences, 2nd ed. Hillsdale, New Jersey: Lawrence Erlbaum Associates, 1988.

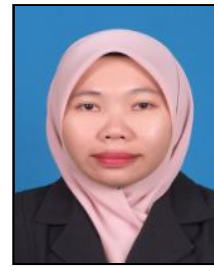

Muslihah Wook was born in Batu Gajah, Perak Malaysia in 1979. She received her master in computer science from Universiti Putra Malaysia in 2003; She received her bachelor in information technology (Hons) from Universiti Utara Malaysia in 2001. Her research interests include data mining technology in education, artificial intelligence in education, and various technologies adoption in organisation. She is currently working as a lecturer a the Department of Computer Science, Faculty of Defence Science and Technology, National Defence University of Malaysia. She has published 11 conference papers and one Q1 journal paper indexed by Scopus. She has became a members of International Association of Computer Science and Information Technology (IACSIT) and Institute of Research Engineers and Doctors (IRED).

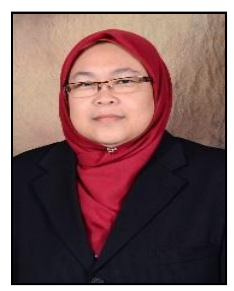

Zawiyah M. Yusof was born in Selangor, Malaysia in 1959. She has received prior education in B.A. (Hons) from UKM, 1984, Post Gd. Dip. (Lib \& Info. Sci) from ITM, 1986, MA (Lib., Arc. \& Info. Studies) from University College London, in 1990 and She received her PhD (Record \& Info. Mgmnt.) from University of Wales, Aberystwyth, in 2000. Currently, she is a professor at UKM. Her research interests include records and information management, information technology and society, knowledge management, and computer, ethics and social. She has published many books and journa articles. She has been invited as a keynote speaker in many conferences.

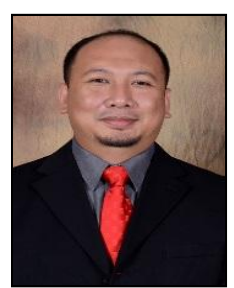

Mohd Zakree Ahmad Nazri was born in $1975 . \mathrm{He}$ has received prior education in diploma (electronic and computing technology) from Ungku Omar Polytechnic, bachelor degree (Syst. Sci.\& Mgmnt.) from UKM, masters and $\mathrm{PhD}$ are both from UTM. Currently, he is a senior lecturer at the center for artificial intelligence technology at UKM and the head of doctoral programme at the Faculty of Information Science and Technology. He has published many books and journals. Before joined UKM, he worked a Motorola Semiconductor (producing PowerPC for Mac), Phillips-JVC, Technip (training) and MEASAT (Binariang). His research interests include data mining, Malay natural language processing, ontology learning, decision support, information retrieval, business intelligence and computational criminology. Currently, he is collaborating with the Royal Malaysia Police in mining spatio-temporal data. 